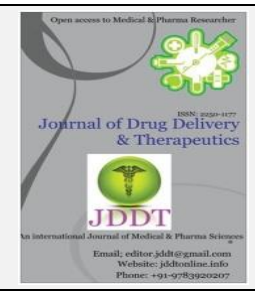

Open $\odot$ Access

Research Article

\title{
Inclusion Complexation in Sulfobutyl Ether Beta Cyclodextrin and Dispersion in Gelucire for Sustained Release of Nifedipine Employing Almond Gum
}

\author{
Ramesh Kanteti *, Meena Achamma, Hemant Kumar Yadav, Tamer Salama Elmarsafawy, Quamrul Islam \\ RAK College of Pharmaceutical Sciences, RAK Medical \& Health Sciences, University, Ras Al Khaimah, United Arab Emirates
}

\begin{abstract}
In the present research investigation, the utility of employing high dissolving forms of nifedipine for sustained release from matrix tablets with almond gum as major release retardant is explored. A poorly soluble BCS class II drug nifedipine is chosen as a model drug. Efforts were made to alter the dissolution characteristics of the drug before it is entrapped in the polymer matrix of almond gum. Inclusion complexation in sulfobutyl ether beta cyclodextrin or solid dispersion in gelucire (50/13) resulted in enhanced dissolution of nifedipine. The high dissolving forms are characterized by x-ray diffraction, differential scanning calorimetry and infra-red spectroscopy. The matrix tablets prepared employing the high dissolving forms exhibited satisfactory characteristics such as hardness, friability, swelling index. The drug release is found to be slow and spread over a period of 12 hours and the release could be modified with changes in nature of high dissolving form and the proportion of almond gum as the major release retardant. Employing high dissolving forms in matrix tablets of almond gum is found to be a novel approach in obtaining slow and complete release of poorly soluble drug such as nifedipine.
\end{abstract}

Keywords: sulfobutyl ether beta cyclodextrin, solid dispersion, nifedipine

Article Info: Received 07 Sep 2019; $\quad$ Review Completed 22 Oct 2019; $\quad$ Accepted 29 Oct 2019; Available online 15 Nov 2019

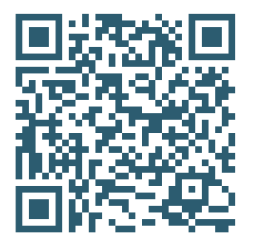

Cite this article as:

Kanteti R, Achamma M, Yadav HK, Elmarsafawy TS, Islam Q, Inclusion Complexation in Sulfobutyl Ether Beta Cyclodextrin and Dispersion in Gelucire for Sustained Release of Nifedipine Employing Almond Gum, Journal of Drug Delivery and Therapeutics. 2019; 9(6):70-78 http://dx.doi.org/10.22270/jddt.v9i6.3681

Ramesh Kanteti, RAK College of Pharmaceutical Sciences, RAK Medical \& Health Sciences, University, Ras Al Khaimah, United Arab Emirates

\section{INTRODUCTION}

New technologies and processes are being developed for existing and new drug molecules to prepare sustained release (SR) and controlled release (CR) dosage forms. SR or CR products provide important benefits over the conventional immediate release (IR) products [1,2]. These include reduced dosing frequency, more favourable plasma concentrations and better patient compliance. Most approaches in the design of SR dosage forms aim to prepare single unit forms such as matrix tablets. For the successful development of an SR dosage form, it is essential that the technology developed is suitable for the drug involved. Biopharmaceutical Classification System (BCS) Class II drugs exhibit poor solubility and permeability characteristics [3]. The development of SR dosage forms for poorly soluble drugs is very challenging. According to Nixon, the major stages involved in drug release from sustained release products into the dissolution fluid are: (1) uptake of dissolution fluid by the product (2) dissolution of the drug substance inside the dosage form and (3) diffusional release of drug into the dissolution fluid [4]. The dissolution of the drug in the matrix tablet will be crucial for the prompt release of the drug. We selected nifedipine as a model drug in the present work as it is reported that nifedipine because of its crystalline form and slow dissolution shows low drug ISSN: 2250-1177 bioavailability [5]. Nifedipine is a calcium channel blocker used in the therapy of angina pectoris and it is reported to have a biological half-life of 2-3 hours [6]. So employing nifedipine as such may not result in prompt release from the SR dosage form and the release is likely to be incomplete as well. So the main objective of the present work is to increase the dissolution rate of nifedipine and employ the high dissolving form in the development of sustained release matrix tablets using almond gum as the major release retardant. In the present investigation, the dissolution rate of nifedipine was increased by employing 2 approaches: i) inclusion complexation in sulfobutyl ether beta cyclodextrin $\left(\left(\mathrm{SBE}_{7}-\beta-\mathrm{CD}\right)\right.$ and ii) by solid dispersion (solvent deposited system) in gelucire and microcrystalline cellulose. $\mathrm{SBE}_{7}-\beta-$ CD is a modified $\beta$ cyclodextrin that has better drug entrapment ability and favourable physical and chemical properties than the parent cyclodextrin. It is reported to be having high solubility (excess $70 \mathrm{~g} / 100 \mathrm{ml}$ ) and minimal toxicity. $\mathrm{SBE}_{7}-\beta-\mathrm{CD}$, which is being explored in the development of injectable products and found to be useful to stabilize drugs, is reported to be safe after intensive chronic safety evaluation [7]. Gelucires contain different combinations of mono, di and triglycerides which are esters of polyethylene glycol and fatty acids. They are inactive additives having both hydrophilic and hydrophobic parts. 
Gelucire 50/13 is a semisolid substance having a hydrophilic and lipophilic balance value of 13 and it melts at $50^{\circ} \mathrm{C}$. Due to its affinity for water, it can be considered as a useful carrier to prepare fast dissolving products by solid dispersion technique [8,9]. In this study, we explored the utility of almond gum in the development of sustained release matrix tablets. Almond gum is an exudate obtained from the plant Amygdalus communis [10]. There are some reports on the binding and release retarding properties of almond gum and it is reported to be useful in the preparation of hydrogel silver nanoparticle [11,12].

\section{MATERIALS \& METHODS}

Nifedipine (gift sample from Julphar Gulf Pharmaceutical Industries UAE), sulfobutyl ether beta cyclodextrin ( $\mathrm{SBE}_{7}-\beta$ CD - Cydex Corp, USA), Gelucire (50/13) - Gattefosse, France (sample given by Genova Life Sciences, Bengaluru), microcrystalline cellulose ( MCC - ), Almond gum is procured from Harekrishna Herbals, Kakinada, India. All other excipients, chemicals and solvents are of analytical grade and were purchased commercially.

All the experiments with nifedipine were carried out under subdued light conditions.

\section{Inclusion complexation of nifedipine in sulfobutyl ether beta cyclodextrin}

\section{Phase solubility study}

Phase solubility studies were done to know the molar ratio of complex formation between nifedipine and sulfobutyl ether beta cyclodextrin as per Higuchi and Connors method [13].

Excess amounts of nifedipine were added to $15 \mathrm{ml}$ of distilled water containing increasing concentrations of $\mathrm{SBE}_{7-}$ $\beta$-CD in $25 \mathrm{ml}$ stoppered glass bottles. The resulting dispersions were shaken at $37^{\circ} \mathrm{C} \pm 0.5^{\circ} \mathrm{C}$ for 3 days in a temperature controlled shaking water bath (SeichemTech SK 330 Pro). At the end of 3 days, a sample dispersion was removed and after filtration through a $0.45 \mu \mathrm{m}$ membrane, estimated for nifedipine content by measuring the absorbance spectrophotometrically at $238 \mathrm{~nm}$ (Shimadzu Model UV 1600)

Phase solubility studies were performed in triplicate. Solubility diagram was drawn between the molar concentration of nifedipine soluble and the molar concentration of SBE7- $\beta$-CD. From the resulting plot, the stability constant for the formation of complex between nifedipine and $\mathrm{SBE}_{7}-\beta-\mathrm{CD}$ was determined by employing the formula

$$
\mathrm{K}_{\mathrm{s}}=\text { Slope } / \mathrm{S}_{0}(1-\text { Slope })
$$

The slope is calculated from the plot (Fig 1) and $S_{0}$ is the equilibrium solubility of nifedipine.

\section{Preparation of inclusion complex}

The inclusion complexes of nifedipine with SBE7- $\beta$-CD were prepared by kneading and freeze-drying procedures in a 1:1 M ratio.

\section{Kneading method (KN)}

The required quantities of nifedipine and $\mathrm{SBE}_{7}-\beta-\mathrm{CD}$ were accurately weighed, added to a mortar and kneaded for 45 min. While carrying out the kneading, little quantity of methanol: water $(20: 80 \mathrm{v} / \mathrm{v})$ solution was added to the kneaded mass to ensure sufficient consistency. The mass obtained was dried at $40^{\circ} \mathrm{C}$ for $48 \mathrm{~h}$, powdered and then passed through a 100-mesh sieve, and stored until further use.

\section{Freeze-drying method (FD)}

Appropriate amounts of nifedipine and $\mathrm{SBE}_{7}-\beta-\mathrm{CD}$ were dissolved in methanol $(8 \mathrm{ml})$ and water $(32 \mathrm{ml})$ respectively. The aqueous and methonolic solutions were then mixed for $24 \mathrm{~h}$ at $25^{\circ} \mathrm{C}$ using a magnetic stirrer. The blended solution was subjected to freezing at $-70^{\circ} \mathrm{C}$ and latter freeze-dried for $48 \mathrm{hrs}$ at $-50^{\circ} \mathrm{C}$ using a freeze-dryer (SP Scientific, Model PRO 3XL). The freeze dried powder was sifted through a 100-mesh sieve and stored until further use.

\section{Preparation of solvent deposited systems of nifedipine-} gelucire-MCC

The solid dispersions (solvent deposited systems) of nifedipine-gelucire $(50 / 13)$ were prepared by solvent evaporation method. $100 \mathrm{mg}$ of Nifedipine was accurately weighed and transferred to a conical flask of $50 \mathrm{ml}$ volume and dissolved in $15 \mathrm{ml}$ of dichloromethane. Now, $200 \mathrm{mg}$ of Gelucire (50/13) is added to this solution and dissolved. In this prepared mixture, $700 \mathrm{mg}$ of microcrystalline cellulose (MCC) was dispersed and agitated with a magnetic stirrer. The solvent was then evaporated under vacuum until a solid residue is formed. The obtained mass was then dried under a vacuum to get a free-flowing powder.

Evaluation of inclusion complexes and solvent deposited systems

\section{Dissolution}

The dissolution of nifedipine from pure drug powder solvent deposited system and the complexes was studied using USP Type II dissolution rate test apparatus (Lab India Model DISSO). Nifedipine or the products equivalent to 10 $\mathrm{mg}$ of nifedipine were added to $900 \mathrm{ml}$ of dissolution medium ( $0.1 \mathrm{~N}$ hydrochloric acid). The paddle was operated at $50 \mathrm{rpm}$ and temperature was maintained at $37^{\circ} \mathrm{C} \pm 1^{\circ} \mathrm{C}$. Samples of dissolution medium were removed at various time points and after filtration, they were assayed for nifedipine dissolved by measuring the absorbance at $238 \mathrm{~nm}$ employing Shimadzu Model UV 1800 spectrophotometer. The findings of dissolution studies are shown in Fig 2 and given in Table 1.

\section{$\mathrm{X}$-ray diffraction}

The powder $\mathrm{x}$ - ray diffraction studies of nifedipine and the prepared products were done employing X-ray powder diffractometer, PANalytical, Model No. X Pert pro employing $\mathrm{Cu} \mathrm{K} \alpha$ radiation. The diffractograms were obtained between $2^{\circ}$ and $40^{\circ}$ at $2 \circ / \mathrm{min}$ in terms of $2 \theta$ angle. A generator current of $30 \mathrm{~mA}$ at a generator tension (voltage) $40 \mathrm{kV}$ was used. The diffractograms of nifedipine and products are shown in Fig.3.

\section{Differential scanning calorimetry (DSC)}

DSC studies were performed to know the physical nature of nifedipine in the prepared products and to find out any interaction between nifedipine, $\mathrm{SBE}_{7}-\beta-\mathrm{CD}$ and gelucire. The calorimeter (Shimadzu DSC $60+$ ) was run at a scanning speed of $10^{\circ} \mathrm{C}$ per minute. The temperature range of heating was $25^{\circ} \mathrm{C}$ to $350^{\circ} \mathrm{C}$. After sealing the samples in aluminium pans, heating was carried out in an inert atmosphere which is maintained by circulating nitrogen gas. The results of the DSC studies are shown in Fig 4.

\section{Fourier-transform infrared spectroscopy}

The infra-red spectroscopic analysis of nifedipine and the products was performed by attenuated total reflectance 
(ATR) sampling interface technique using Agilent Model Cary 630. Different spectra obtained are shown in Fig 5.

\section{Preparation of matrix tablets employing high dissolving forms}

The composition of different matrix tablets is given in Table 2. The different excipients are first sieved through sieve No.80 to get uniform sized powders. The required quantities of various of these powders are taken into a mortar and blended uniformly. Little quantities of distilled water were added and blended well until sufficient cohesive mass was obtained. The mass is now passed through sieve No. 18 and the resulting granules are dried at $37^{\circ} \mathrm{C}$. The dried granules are subjected to dry screening by employing sieve No. 35 . After lubrication, these granules were mixed in a plastic bag and then compressed into tablets.

The flow properties of granules are found out before they are compressed. The attributes of various tablets are determined. The flow properties of granules and tablet characteristics are given in Tables $3 \& 4$.

\section{Determination of swelling index}

The swelling behaviour of matrix tablets was determined at $37^{\circ} \mathrm{C} \pm 0.5^{\circ} \mathrm{C}$ in simulated gastric fluid. Three tablets from each formulation were individually kept in a petri dish containing $30 \mathrm{ml}$ of the fluid. At the end of six hours the tablets are removed, blotted with a tissue paper and weighed. The extent of swelling was calculated from the formula given below:

$$
\text { Swelling index }=\left[\left(M_{t}-M_{o}\right) / M_{o}\right] \times 100
$$

where, $\mathrm{M}_{t}$ and $\mathrm{M}_{\mathrm{o}}$ are the weights of tablet at time $=\mathrm{t}$ and time $=0$, respectively.

\section{Drug release studies}

The release of nifedipine from the matrix tablets was estimated by utilizing USP Dissolution Rate Test Apparatus Type I. Release from different formulations was characterized in simulated gastric fluid for first 2 hours and in simulated intestinal fluid for the remaining 10 hours. The extent of drug release was found out by measuring the absorbance (at $238 \mathrm{~nm}$ ) of release medium samples that are removed at regular intervals.

\section{RESULTS AND DISCUSSION}

\section{Phase solubility study}

The phase solubility diagram of nifedipine as a function of the concentration of $\mathrm{SBE}_{7-} \beta-\mathrm{CD}$ is shown in Fig 1 . The amount of nifedipine soluble increased linearly with the amount of $\mathrm{SBE}_{7}-\beta-\mathrm{CD}$.

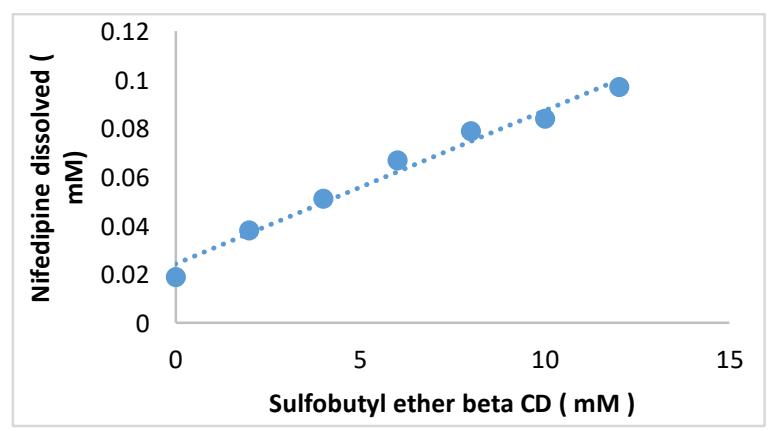

Fig 1: Phase solubility diagrams of nifedipine with $\mathrm{SBE}_{7}-$ $\boldsymbol{\beta}-\mathrm{CD}$

The slope of the line was less than one which indicated that the complex formed is in 1:1 molar ratio. The stability constant of the complex calculated was $262.5 \mathrm{M}^{-1}$ which suggests that the complex will have good stability and dissolution required for high bioavailability. Complexes with very low or high stability constants are not useful for increasing absorption because they are too weak or very strong respectively ${ }^{[14]}$.

\section{Characterization of inclusion complexes and gelucire} dispersions

\section{Dissolution studies}

The results of the dissolution studies of pure drug nifedipine, the inclusion complexes and dispersion in gelucire are shown in Fig 2 and given in Table 1. It is observed that the complexes and the dispersion exhibited a rapid dissolution in comparison to that of the pure drug nifedipine. Out of the three fast dissolving forms, the dispersion in gelucire showed highest dissolution rate. At the end of 30 minutes, the pure drug showed less than $10 \%$ dissolution, the kneaded and freeze dried complexes exhibited $44 \%$ and $70 \%$ dissolution respectively, whereas the dispersion in gelucire resulted in $85 \%$ dissolution. To assess the increase in dissolution, Khan has suggested the term dissolution efficiency (D.E) [15]. Pure nifedipine showed $\mathrm{DE}_{30}$ of $4.16 \%$ and the complexes showed $14.12 \%(\mathrm{KN})$ and $28.72 \%$ (FD) respectively, whereas the dispersion in gelucire exhibited highest $\mathrm{DE}_{30}$ of $40.62 \%$. The $\mathrm{K}_{1}$ values for the freeze dried \& kneaded freeze dried complexes and gelucire dispersions were higher (0.0218 $\mathrm{min}^{-1} \& 0.0103 \mathrm{~min}^{-1}$ and $\left.0.0453 \mathrm{~min}^{-1}\right)$ compared to pure drug $\left(0.0018 \mathrm{~min}^{-1}\right)$. The extent of increase in dissolution observed from the different products was assessed by finding out the difference (f1) and similarity factors (f2) as per the model proposed by Moore and Flanner [16]. The difference factor $\mathrm{f} 1$ is proportional to the average difference between the two profiles, whereas similarity factor $\mathrm{f} 2$ is inversely proportional to the average squared difference between the two profiles. Generally, if the f1 values are above 15 and $\mathrm{f} 2$ values are less than 50 , then the 2 profiles compared are considered as different. In the present investigation, when the dissolution profile of pure drug is compared with the fast dissolving products the f1 values are found to be, 77.94, $87.06 \& 90.25$ and $\mathrm{f} 2$ values as $31.23,17.91 \& 11.89$, for kneaded, freeze dried and gelucire dispersions respectively suggesting that the increase in dissolution observed is significant. The mechanism of increased dissolution is investigated and discussed in detail in the sections below. In case of the gelucire dispersion, the presence of microcrystalline cellulose (MCC) on which the dispersion is deposited might also have contributed to the higher dissolution as deposition on MCC will result in significant increase in surface area of the dispersion making the product more dispersed in the dissolution medium.

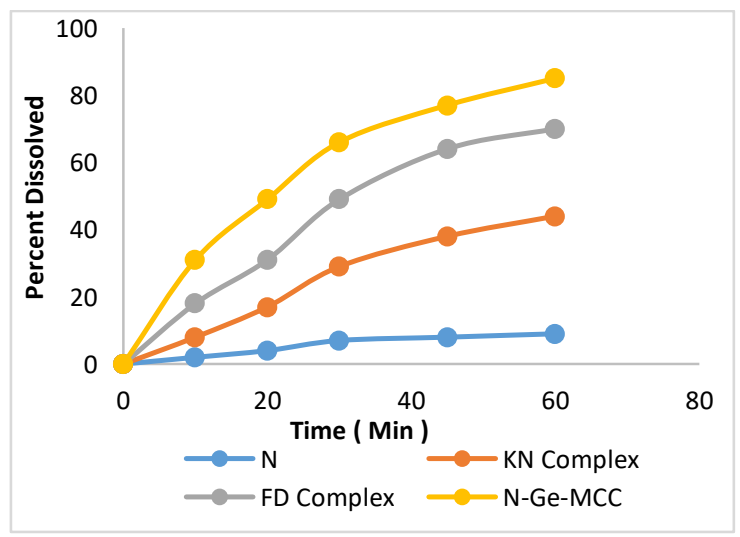

Fig 2 Dissolution profiles of nifedipine, inclusion complexes and gelucire dispersion 
Table 1 Dissolution parameters of fast dissolving products of nifedipine

\begin{tabular}{|c|c|c|c|c|}
\hline \multirow[b]{2}{*}{ Product } & \multicolumn{4}{|c|}{ Characteristic* } \\
\hline & $\begin{array}{c}\text { Drug Content } \\
\text { (\%) }\end{array}$ & $\begin{array}{c}T_{50} \\
(\mathrm{~min})\end{array}$ & $\begin{array}{l}\text { D.E } \\
\text { (\%) }\end{array}$ & $\begin{array}{c}\mathrm{K}_{1} \\
\left(\min ^{-1}\right) \\
{\left[\mathrm{r}^{2}\right]}\end{array}$ \\
\hline Pure drug & -- & $>60$ & $4.16 \pm 0.91$ & $\begin{array}{c}0.0018 \\
{[0.9834]}\end{array}$ \\
\hline FD complex & $12.62 \pm 0.31$ & $31.1 \pm 1.87$ & $28.72 \pm 1.25$ & $\begin{array}{c}0.0218 \\
{[0.9885]}\end{array}$ \\
\hline KN complex & $12.81 \pm 0.29$ & $>60$ & $14.12 \pm 1.37$ & $\begin{array}{c}0.0103 \\
{[0.9921]}\end{array}$ \\
\hline N-Ge-MCC & $9.11 \pm 0.63$ & $20.1 \pm 1.64$ & $40.62 \pm 1.19$ & $\begin{array}{c}0.0453 \\
{[0.9955]}\end{array}$ \\
\hline
\end{tabular}

FD - Freeze dried; KN - Kneaded; * Average of 3 determinations

\section{Mechanism of increased dissolution}

To assess the cause of hike in the dissolution rate of nifedipine from the prepared products, $\mathrm{x}$-ray diffraction and differential scanning calorimetry studies were carried out.

\section{$\mathrm{X}$ - ray diffraction}

The nifedipine inclusion complexes and the solid dispersion were evaluated using x-ray diffraction (Fig 3). Pure drug nifedipine exhibited sharp diffraction peaks indicating its crystalline nature whereas the peaks have significantly disappeared in the freeze dried complex and the dispersion in gelucire.This indicates that the crystalline drug is converted into an amorphous state in these two high dissolving products. However, in the case of the complex made by kneading method, though there is a reduction in the peaks, the diffraction pattern still exhibited a good number of peaks. This is probably the reason why the kneaded complex showed lesser dissolution rate thanthe freeze dried complex.
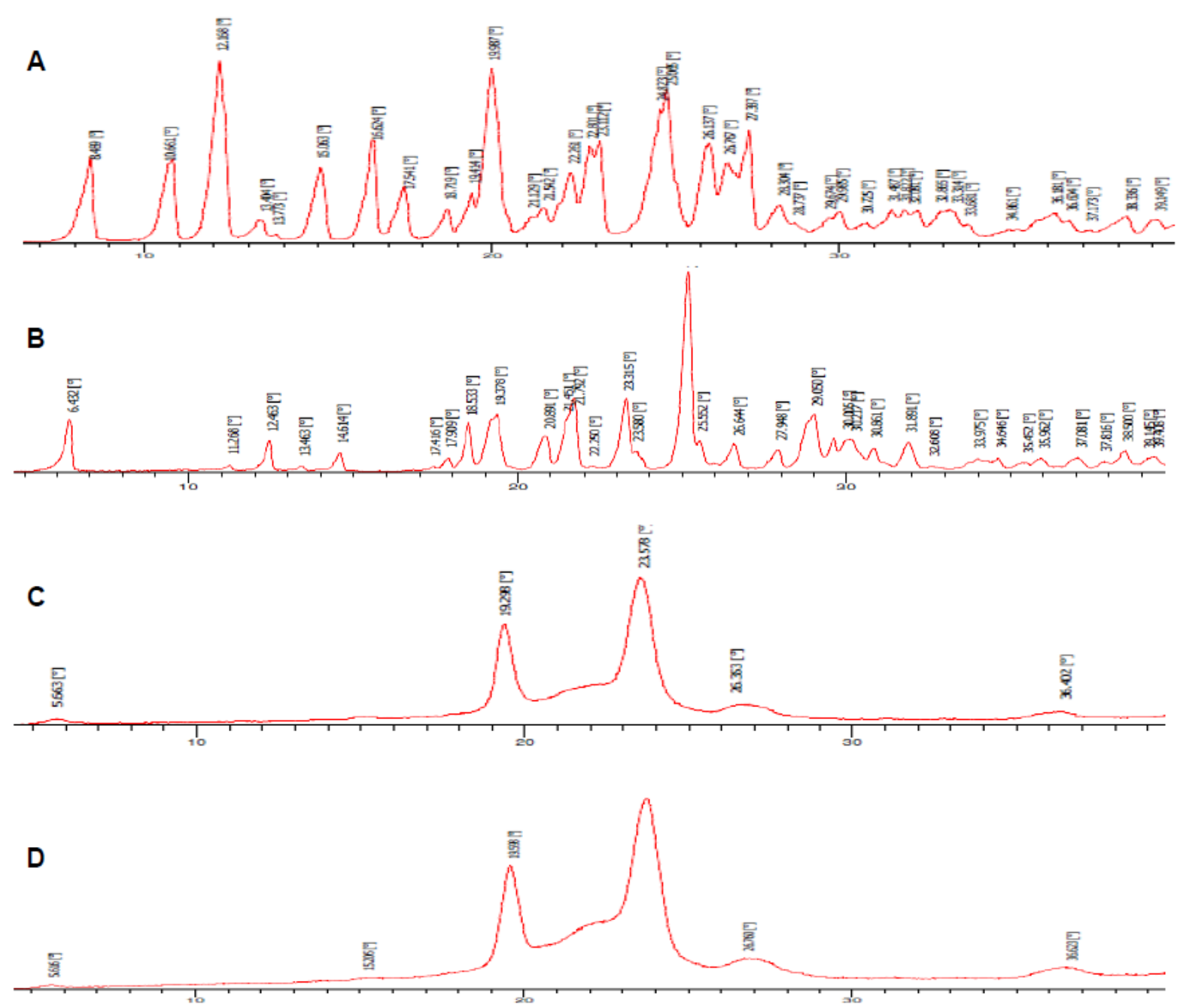

Fig $3 \mathrm{X}$ ray diffractograms of Nifedipine [A]; Kneaded complex [B]; Freeze dried complex [C] ; Gelucire dispersion [D] 


\section{Differential scanning calorimetry}

The endotherms of nifedipine and the high dissolving products are shown in Fig 4. The endotherm

of the pure drug nifedipine showed a sharp peak at $171^{\circ} \mathrm{C}$ which is because of the melting of the drug nifedipine. In case of the inclusion complex (FD) and the solid dispersion, no melting peak was observed indicating that nifedipine is no more in crystalline state but existed in amorphous solid solution state in the products. In case of kneaded complex, there is a small peak which is broad is observed near the melting point of nifedipine. This transformation into amorphous form and dispersion of the drug in a finely subdivided state explains why in the case of complexes and gelucire dispersion, the dissolution of nifedipine is higher than that of the pure drug.

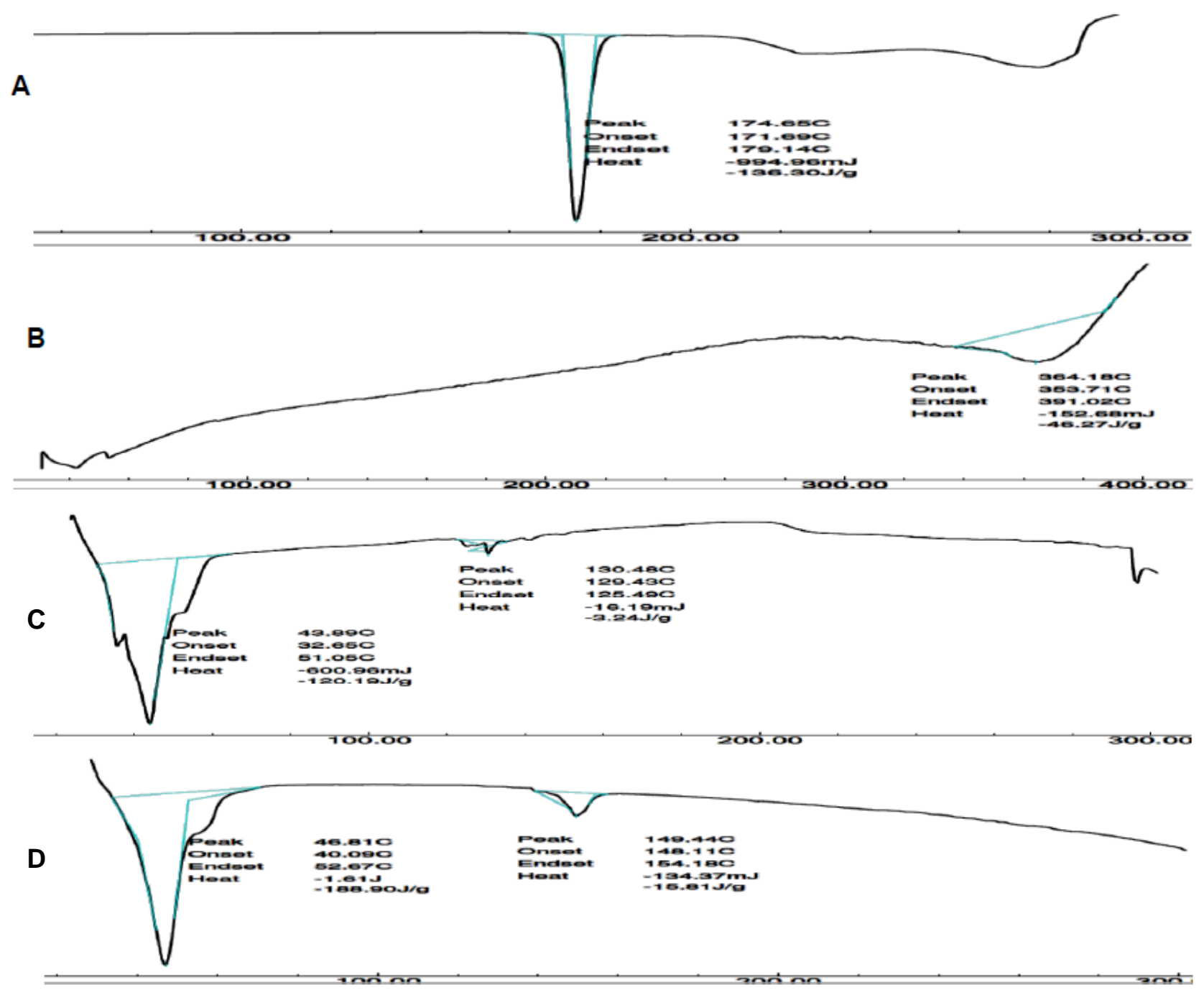

Fig 4 DSC thermograms of Nifedipine [A]; Freeze dried complex [B]; N-Gelucire dispersion [C] ; Kneaded complex [D]

So the $\mathrm{x}$ ray diffraction and differential scanning calorimetric studies confirm the existence of nifedipine in amorphous state in the freeze dried inclusion complex and the dispersion in gelucire, resulting in higher dissolution. The order of decreasing dissolution for the 3 different products is $\mathrm{N}-\mathrm{Ge}-\mathrm{MCC}>$ freeze dried complex > kneaded complex.

\section{Fourier-transform infrared spectroscopy}

FTIR spectroscopy (Fig 5) was carried out to detect any chemical interaction between nifedipine and the two polymers employed to prepare the fast dissolving products. Nifedipine exhibited principal IR absorption peaks at 3331 $\mathrm{cm}^{-1}$ (N-H stretching), $1679 \mathrm{~cm}^{-1}$ (C=0 ester), $1625 \mathrm{~cm}^{-1}$ $\left(\mathrm{C}=\mathrm{C}\right.$ aromatic), $1530 \mathrm{~cm}^{-1}\left(\mathrm{NO}_{2}\right)$ and $1380 \mathrm{~cm}^{-1}\left(-\mathrm{C}-\mathrm{CH}_{3}\right)$ [17]. The FTIR spectra of both the inclusion complexes and gelucire dispersion contain all the contributions coming from nifedipine without exhibiting any dissimilarities. This confirms that the drug did not undergo any chemical change in the presence of the two polymers in the high dissolving forms. However, in the inclusion complex, the intensity of absorption band at $3331 \mathrm{~cm}^{-1}$, due to stretching vibrations of the $\mathrm{N}-\mathrm{H}$ bond in the dihydropyridine ring of nifedipine is reduced which could be due to the formation of an inclusion complex, this is in agreement with the reported work of Mielcarek and Sadaj who observed a similar change upon kneading/roll mixing of nifedipine with $\beta$-CD in a 1:1 molar ratio [18]. There is a small shift in the position of the peak due to other potential functional group $(\mathrm{C}=0)$, that can be involved in the complexation. The peak at $1679 \mathrm{~cm}^{-1}$ has slightly broadened and shifted to higher frequencies in the inclusion complex. 


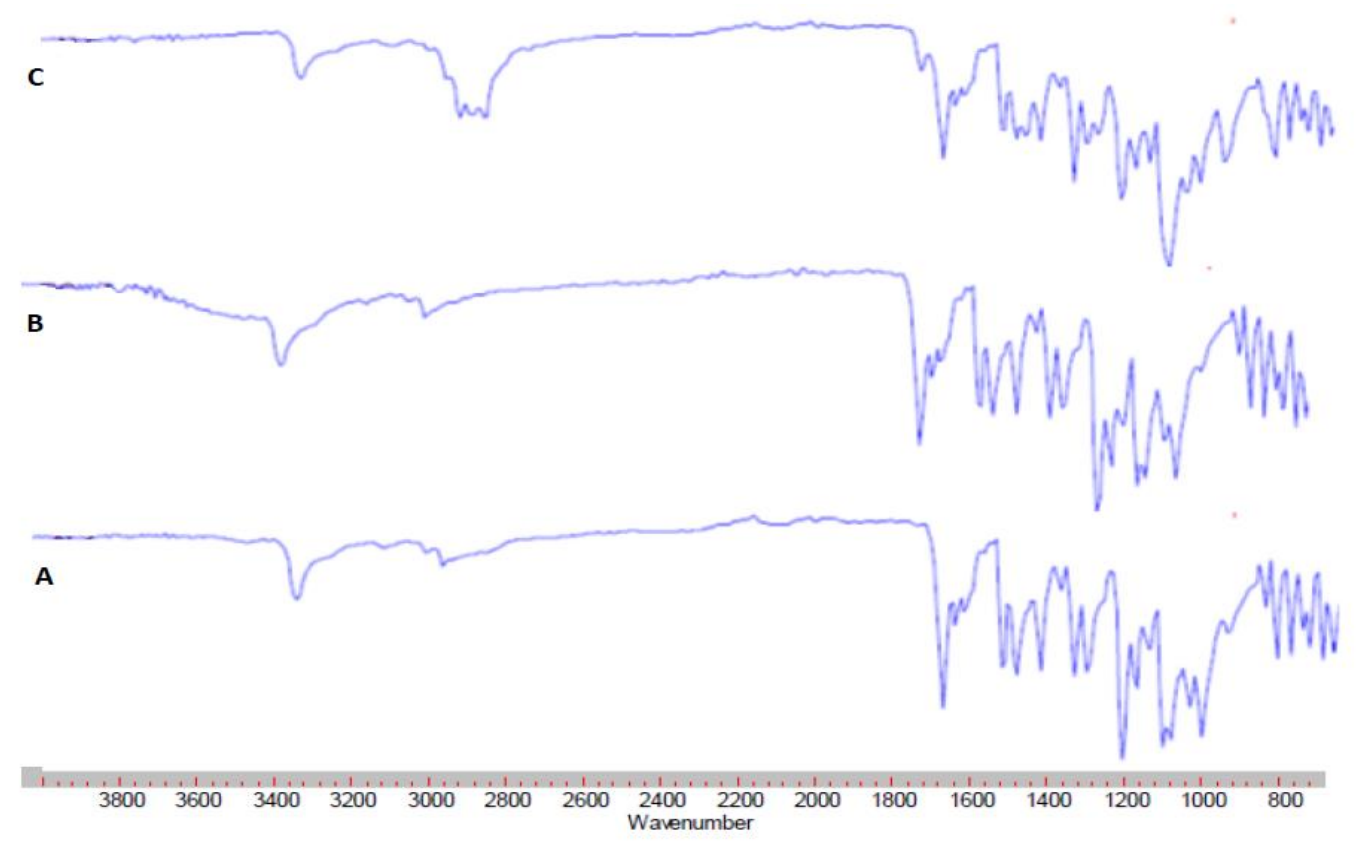

Fig 5 FTIR spectra of nifedipine (A); inclusion complex (B); dispersion in gelucire (C)

\section{Preparation and characterization of matrix tablets}

Six different formulations of matrix tablets were developed employing the high dissolving forms and almond gum as the major release retardant. The composition of various matrix tablets is given in Table 2 . The prepared fast dissolving products of nifedipine (inclusion complex or N-Ge-MCC) were mixed with the remaining excipients and wet granulated. Wet granulation technique used, is found to be suitable and resulted in free flowing granules. The free flowing nature of the granules enabled their easy compression. The data given in Table 3 suggests satisfactory flow nature of granules.The higher angle of repose values of $\mathrm{N}$-Ge-MCC ( inspite of the presence of MCC) could be due to the presence of gelucire as it is waxy in nature and granules prepared employing gelucire are usually expected to be less free flowing than other formulations. However the Carr's index of all the formulations including the formulation F4 ( with N-Ge-MCC ) have exhibited values which are suggestive of the flow character that is classified as excellent.

Table 2 Composition of different formulations of matrix tablets of nifedipine

\begin{tabular}{|c|c|c|c|c|c|c|}
\hline Ingredient (mg) & F1 & F2 & F3 & F4 & F5 & F6 \\
\hline Nifedipine & 20 & -- & -- & -- & -- & -- \\
\hline $\begin{array}{c}\text { Inclusion complex } \\
\text { (FD) }\end{array}$ & -- & 110 & -- & -- & -- & -- \\
\hline $\begin{array}{c}\text { Inclusion complex } \\
\text { (KN) }\end{array}$ & -- & -- & 110 & -- & -- & -- \\
\hline N-Ge-MCC & -- & -- & -- & 210 & 210 & 210 \\
\hline Almond gum & 100 & 100 & 100 & 100 & 50 & 50 \\
\hline HPMC & 50 & 50 & 50 & 50 & 100 & 75 \\
\hline Sodium CMC & 50 & 50 & 50 & 50 & 100 & 75 \\
\hline Lactose & 260 & 170 & 170 & 70 & 20 & 70 \\
\hline Magnesium stearate & 10 & 10 & 10 & 10 & 10 & 10 \\
\hline Talc & 10 & 10 & 10 & 10 & 10 & 10 \\
\hline
\end{tabular}

FD - Freeze dried ; KN - Kneaded ; HPMC - Hydroxy propyl methyl cellulose ; N- Nifedipine ; Ge - Gelucire ; MCC Microcyrstalline cellulose ; CMC - Carboxy methyl cellulose

Table 3 Characteristics of granules of different formulations

\begin{tabular}{|c|c|c|c|c|}
\hline \multirow{2}{*}{ Formulation } & \multicolumn{3}{|c|}{ *Characteristics } \\
\cline { 2 - 5 } & Bulk Density & Tapped Density & Angle of Repose & Carr's index \\
\hline F1 & $1.31 \pm 0.026$ & $1.38 \pm 0.057$ & $25.49 \pm 0.25$ & $5.07 \pm 0.11$ \\
\hline F2 & $1.07 \pm 0.026$ & $1.13 \pm 0.049$ & $26.26 \pm 0.49$ & $5.30 \pm 0.12$ \\
\hline F3 & $1.23 \pm 0.041$ & $1.28 \pm 0.025$ & $25.78 \pm 0.30$ & $3.91 \pm 0.13$ \\
\hline F4 & $1.17 \pm 0.039$ & $1.27 \pm 0.021$ & $30.74 \pm 0.46$ & $7.87 \pm 0.21$ \\
\hline F5 & $1.41 \pm 0.017$ & $1.49 \pm 0.017$ & $23.26 \pm 0.39$ & $5.36 \pm 0.29$ \\
\hline F6 & $1.38 \pm 0.024$ & $1.44 \pm 0.024$ & $19.78 \pm 0.17$ & $4.17 \pm 0.25$ \\
\hline
\end{tabular}

* Average of 3 determinations 
Table 4 Characteristics of various matrix tablets

\begin{tabular}{|c|c|c|c|c|c|}
\hline \multirow[b]{2}{*}{ Formulation } & \multicolumn{5}{|c|}{${ }^{*}$ Characteristics } \\
\hline & $\begin{array}{c}\text { Drug content } \\
(\%)\end{array}$ & $\begin{array}{l}\text { Hardness } \\
\left(\mathrm{kg} / \mathrm{cm}^{2}\right)\end{array}$ & $\begin{array}{c}\text { Average weight } \\
\text { (mg) }\end{array}$ & $\begin{array}{c}\text { Friability } \\
(\%)\end{array}$ & $\begin{array}{c}\text { Swelling } \\
\text { index (\%) }\end{array}$ \\
\hline $\mathrm{F} 1$ & $99.79 \pm 0.21$ & $7.18 \pm 0.20$ & $502.98 \pm 0.29$ & $0.35 \pm 0.61$ & $75.17 \pm 1.21$ \\
\hline F2 & $99.88 \pm 0.14$ & $7.23 \pm 0.11$ & $498.30 \pm 0.67$ & $0.19 \pm 0.07$ & $74.19 \pm 0.91$ \\
\hline F3 & $100.49 \pm 0.27$ & $7.02 \pm 0.35$ & $501.39 \pm 0.54$ & $0.55 \pm 0.11$ & $75.38 \pm 1.03$ \\
\hline $\mathrm{F} 4$ & $100.26 \pm 0.20$ & $7.46 \pm 0.12$ & $499.89 \pm 0.76$ & $0.44 \pm 0.12$ & $77.97 \pm 1.63$ \\
\hline F5 & $99.56 \pm 0.34$ & $7.17 \pm 0.13$ & $502.45 \pm 0.21$ & $0.67 \pm 0.24$ & $59.97 \pm 2.31$ \\
\hline F6 & $101.33 \pm 0.41$ & $6.89 \pm 0.22$ & $498.67 \pm 0.52$ & $0.73 \pm 0.21$ & $63.97 \pm 1.45$ \\
\hline
\end{tabular}

The various characteristics of compressed tablets were determined. The tablets were evaluated with respect to their hardness, friability, drug content, weight uniformity and swelling index and the respective values are shown in Table 4. The hardness of tablets of all formulations was in the range of 6.89 to $7.46 \mathrm{~kg} / \mathrm{cm}^{2}$. The friability of the tablets of all the formualtions was less than $1 \%$. The tablet formulations in all the prepared batches contained nifedipine within $100 \pm 5 \%$ of expected content. As such, all the batches of the tablets were of good quality with regard to hardness, friability and drug content. All tablets are found to be uniform in weight with low standard deviation.

\section{Swelling index study}

In general, the sustained release matrix tablets should not disintegrate during the entire length of drug release process. During the release, on exposure to the release medium, the tablets will exhibit swelling and the extent of swelling depends on the nature of polymers employed. The presence of hydrophilic polymers increases the swelling of the matrix tablets. Tablets that exhibit more swelling will have more retarding effect on the drug release. This is because with the increase in the swelling, the distrance the drug has to transverse to get released will be more. Also the hydrophilic polymers that show more swelling, form a gelatinous layer around the tablet resultiing in more retarding effect of drug diffusion through the swollen viscous layer [19].

In the present study, formulations F1 to F4 which had higher amount of almond gum showed more swelling index than the formulations F5 and F6 in which the proportion of almond gum is reduced and the amounts of HPMC and sodium CMC are increased. This could be because of higher swelling ability of almond gum compared to HPMC or sodium CMC. These differences in swelling index also reflected in the different extents of drug release that was observed between F4 and F5 \& F6 formulations which contained same type of high dissolving form (the gelucire dispersion ) of nifedipine, discussed more in detail below.

\section{Drug release}

The various drug release profiles are shown in Fig 6. The main objective of present study is to evaluate the usefulness of employing high dissoving forms of nifedipine in obtaining controlled and complete release of nifedipine from the matrix tablets. This is verified in formulations F1 to F4. In case of formulation $\mathrm{F} 1$ in which only pure nifedipine was used, the drug release is found to be very slow and at the end of 12 hours, less than $30 \%$ of the drug was released. This is because of the poor solubility and dissolution of the drug. Whereas in F2 and F3 in which the inclusion complexes prepared by kneading and freeze drying are employed respectively, the release is found to be faster. This is because of the higher dissolution of nifedipine from the complexes. However it may be also observed that in between the freeze dried and kneaded complex, the F3 tablets which had freeze dried complex, showed nearly $80 \%$ release whereas F2 has exhibited only $60 \%$ drug release at the end of 12 hours. With all the formulation factors remaining constant, this difference is only because of the differnce in the extent of dissolution oberved between the freeze dried and kneaded complexes. But although in F2 \& F3 formulations, the release is faster, it is still incomplete at the end of 12 hours. Whereas in F4 formulation, which contained the gelucire dispersion from which the drug dissolution was highest, has shown faster release than F2 \& F3 but it is controlled and complete at the end of 12 hours. The various drug release characteristics are given in Table 5.

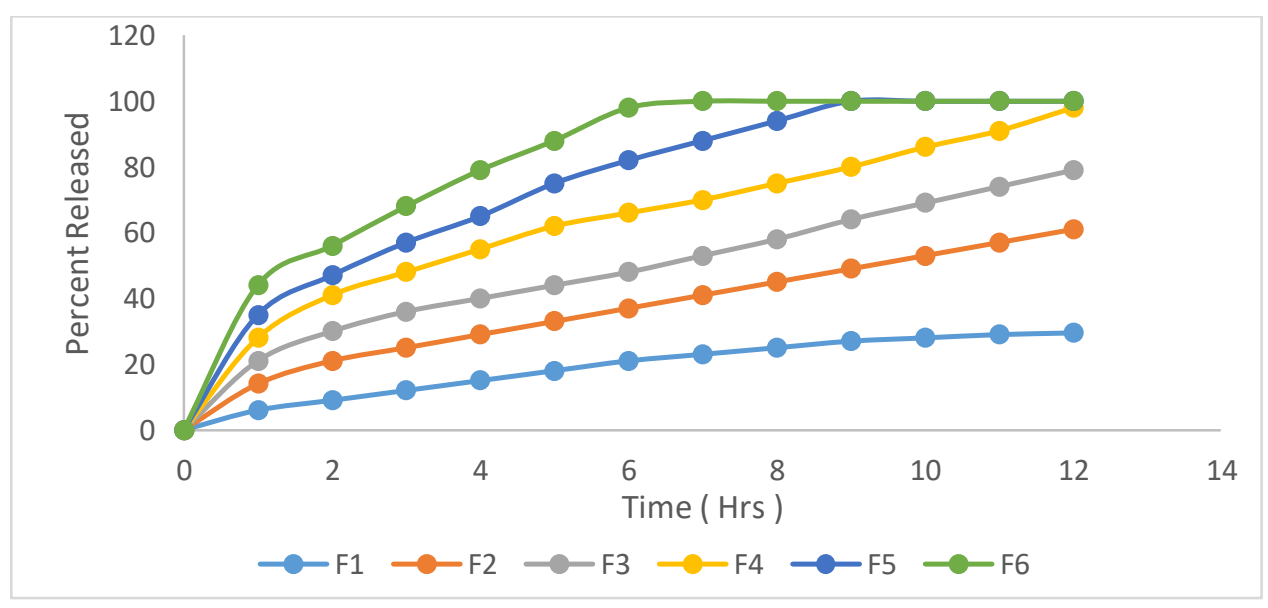

Fig 6 Drug release profiles of various matrix tablet formulations 
To know the drug release mechanism, the data are analyzed as per first order, Higuchi [20] and Peppas [21] models. The model that best fits the release data was evaluated by correlation coefficient $\left(r^{2}\right)$. The $r^{2}$ values in various models is given in Table 5 . When the amount released was plotted against square root of time, it gave straight lines with high $\mathrm{r}^{2}$ values indicating that the drug release is by diffusion. The release followed first order kinetics because the correlation coefficient values are higher than for the zero order (values not shown in the table). The ' $n$ ' values of Peppas plot ranged between 0.5017 and 0.7847 suggesting the release is nonFickian anomalous diffusion. Accordingly, the drug release from these matrix tablets involves penetration by dissolution fluid, dissolution of the drug in dissolution fluid and diffusion of the dissolved drug.

Table 5 Drug release characteristics of various nifedipine matrix tablets

\begin{tabular}{|c|c|c|c|c|c|c|}
\hline \multirow[b]{2}{*}{ Formulation } & \multicolumn{3}{|c|}{ Correlation coefficinet $\left(\mathrm{r}^{2}\right)$} & \multirow[b]{2}{*}{$\mathrm{K}_{1}\left(\mathrm{hr}^{-1}\right)$} & \multirow{2}{*}{$\mathrm{K}_{\mathrm{H}}(\mathrm{mg} \cdot \mathrm{h})$} & \multirow{2}{*}{$\begin{array}{c}\text { Korsemeyer- } \\
\text { Peppas } \\
\text { 'n value' }\end{array}$} \\
\hline & $\begin{array}{l}\text { First- } \\
\text { order }\end{array}$ & Higuchi & $\begin{array}{l}\text { Korsemeyer- } \\
\text { Peppas }\end{array}$ & & & \\
\hline F1 & 0.9832 & 0.9937 & 0.9934 & 0.0023 & 10.38 & 0.7847 \\
\hline F2 & 0.9931 & 0.9916 & 0.9919 & 0.0103 & 18.72 & 0.6849 \\
\hline F3 & 0.9357 & 0.9754 & 0.9862 & 0.0211 & 23.05 & 0.6579 \\
\hline F4 & 0.9839 & 0.9853 & 0.9941 & 0.0315 & 27.14 & 0.6015 \\
\hline F5 & 0.9881 & 0.9934 & 0.9872 & 0.3949 & 32.84 & 0.5346 \\
\hline F6 & 0.9845 & 0.9847 & 0.9581 & 0.6003 & 38.63 & 0.5017 \\
\hline
\end{tabular}

\section{Statistical analysis of drug release profiles}

A statistical analysis is performed to compare the drug release profiles of various matrix tablet formulations. Analysis of variance (ANOVA) was performed by using two factor completely randomized design (CRD) by employing MSTATC statistical analysis software. The results of ANOVA analysis for products are shown in Table 6.

According to the results of ANOVA, the percent released was found to be highly significantly different at each time level
$(\mathrm{P}<0.001)$ and among the drug products $(\mathrm{P}<0.01)$, implying time with drug product interaction was highly significant (at $\mathrm{P}<0.01$ ), i.e. that the release profiles were not parallel. This interaction indicated that the mean difference of percent released among different drug products was not constant at any two points of time considered. The calculated $F$ value of treatment groups is greater than tabulated $\mathrm{F}$ value (at 0.01 level of probability). The results of ANOVA showed that the drug products were highly significantly different in terms of percent released at each time point.

Table 6 Analysis of variance (ANOVA) of the drug release from different formulations

\begin{tabular}{|c|c|c|c|c|c|}
\hline Source of Data & $\begin{array}{c}\text { Degrees of } \\
\text { Freedom }\end{array}$ & Sum of Squares & $\begin{array}{c}\text { Mean of } \\
\text { Squares }\end{array}$ & F value & P \\
\hline Time (A) & 11 & 57181.062 & 5198.28 & 11802.58 & $0.000^{* *}$ \\
\hline Percent Drug Released (B) & 5 & 112412.630 & 22482.53 & 51046.11 & $0.000^{* *}$ \\
\hline Interaction (AB) & 55 & 7105.413 & 129.19 & 293.32 & $0.000^{* *}$ \\
\hline Error & 144 & 63.423 & 0.440 & & \\
\hline Total & 215 & 176762.528 & & & \\
\hline
\end{tabular}

\section{CONCLUSION}

From the results of the present investigation, it can be concluded that inclusion complexation in sulfobutyl ether beta cyclodextrin and dispersion in gelucire gave higher dissolution of nifedipine. The higher dissolution is because of crystalline nifedipine being converted into amorphous form. Compared to the inclusion complexes, nifedipine dispersed in gelucire and microcrystalline cellulose gave highest dissolution. Sustained release matrix tablets of nifedipine could be prepared by using these fast dissolving forms and by employing almond gum a major release retardant. The release could be modified by changing the type of fast dissolving form and proportion of almond gum. The matrix tablets prepared by employing gelucire dispersion gave slow and complete release. Almond gum is found to be suitable as a good release retardant. Employing gelucire dispersions of nifedipine and almond gum is a promising new approach to obtain the sustained release of poorly water soluble drugs such as nifedipine.

\section{ACKNOWLEDGEMENT}

The authors express their gratitude to the President of RAK Medical \& Health Sciences University, UAE and Dean RAK College of Pharmaceutical Sciences for their encouragement and support in carrying out the research.

\section{CONFLICT OF INTEREST}

The authors declare no conflict of interest. 


\section{REFERENCES}

1. Nowsheen G, Archana B. Naltrexone: A review of existing sustained drug delivery systems and emerging nano-based systems. J Control Release. 2014; 183:154-166.

2. Varaporn B, Junyapraserta G. Release profile comparison and stability of diltiazem-resin microcapsules in sustained release suspensions. Int J Pharm. 2008; 352(1):81-91.

3. Amidon GL, Lennerlas $H$, Shah VP, Crison JR. A theoretical basis for a biopharmaceutic drug classification: The correlation of in vitro drug product dissolution and in vivo bioavailability. Pharm Res. 1995; 12:413-20.

4. Nixon, J.R., 1983. Release characterization of microcapsules. In: Lim, F. (Ed.), Biomedical Applications of Microcapsulation. CRC Press, Boca Raton, FL, p. 19. Peppas NA., Sahlin,

5. Benita S, Barkai A, Pathak YV. 1990. Effect of drug loading extent on the in vitro release kinetic behavior of nifedipine from polyacrylate microspheres. J. Control. Rel. 1990; 12:213.

6. AHFS Drug Information. 2018 published by American Society of Health System Pharmacists, p.2005-2012

7. Okimoto K, Rajewski RA, Uekama K, Jona JA, Stella VJ. The interaction of charged and uncharged drugs with neutral (HPbeta-CD) and anionically charged ( $\mathrm{SBE}_{7}$-beta-CD) betacyclodextrins. Pharm Res. 1996; 13:256-1264

8. Sheng QI, Delphine M, Duncan QM. An Investigation into the Mechanism of Dissolution Rate Enhancement of Poorly WaterSoluble Drugs from Spray Chilled Gelucire 50/13 Microspheres J Pharm Sci 2010; 99(1):262-274

9. Dordunoo SK, Ford JL, Rubinstein MH. Solidification studies of polyethylene glycols, gelucire $44 / 14$ or their dispersions with triamterene or temazepam. J Pharm Pharmacol 1996; 48:7829

10. Bouaziz, F, Ben Romdhane, M et al. Healing efficiency of oligosaccharides generated from almond gum (Amygdalus communis) on dermal wounds of adult rats. J Tissue Viability. 2014; 23(3):98-108.
11. Sarojini A, Kunam DS, Manavalan R, Jayanthi B. Effect of natural almond gum as a binder in the formulation of diclofenac sodium tablets Int J Pharm Sci Res. 2010; 1(3):5560.

12. Syed AH, Jaisankar V. An eco-friendly synthesis, characterization and antibacterial applications of novel almond gum - poly(acrylamide) based hydrogel silver nanocomposite Polym Test. 2017; 62 (10):1016 -1029.

13. Higuchi $\mathrm{T}$, Connors A. Phase-solubility techniques. In: Advances in analytical chemistry instrumentation. New York, NY: Wiley Interscience; 1965; 117-211.

14. Carrier RL, Miller LA, Ahmed I. The utility of cyclodextrins for enhancing oral bioavailability. J Control Release. 2007; 123:78-99.

15. Khan KA. The concept of dissolution efficiency. J Pharm Pharmacol. 1975; 27:48-9.

16. Moore JW and Flanner HH. Mathematical comparison of dissolution profiles. Pharm. Tech. 1996; 20(6):64-75.

17. Ali SL, In Analytical Profiles of Drug Substances, K. Florey, Ed., Academic Press Inc., New York 1989, p. 221.

18. Mielcarek J, Sadaj A. Inclusion compounds of nifedipine and other 1, 4-dihydropyridine derivatives with cyclodextrins I. Complexation of nifedipine with -cyclodextrins Acta. Pol. Pharm 1994; 51:15.

19. Ghori, M.U, Conway, B.R. Hydrophilic matrices for oral control drug delivery. Am. J. Pharmacol. Sci. 2015; 3:103-109

20. Higuchi T. Mechanism of sustained action medication. Theoretical analysis of rate of release of solid drugs dispersed in solid matrices. J Pharm Sci. 1963; 52(12):1145-1149.

21. Korsmeyer RW, Gurny R, Doelker E, Buri P, Peppas NA. Mechanisms of solute release from porous hydrophilic polymers. Int J Pharm. 1983; 15:25-35. 